\title{
Sustainable, proportionate and cost-effective action plans to deliver Air Quality Objectives
}

\author{
N. S. Leksmono ${ }^{1}$, B. E. A. Fisher ${ }^{2}$, J. G. Irwin ${ }^{2}$, K. A. Ling ${ }^{1}$ \\ \& J. W. S. Longhurst ${ }^{1}$ \\ ${ }^{I}$ Air Quality Management Resource Centre, Faculty of Applied Sciences, \\ University of the West of England, Bristol, UK \\ ${ }^{2}$ Environment Agency, Risk and Forecasting, Reading, UK
}

\begin{abstract}
This paper examines the application of three principles: sustainability, proportionality and cost-effectiveness within the development of air quality action plans. A focus is given to air quality problems in English and Welsh local authorities arising from industrial emissions. It also explores the relationship of the Local Air Quality Management (LAQM) regime introduced by the Environment Act 1995 and the Integrated Pollution Prevention and Control (IPPC) regime regulated by the Pollution Prevention and Control Act 1999. Evidence from a questionnaire survey and case study research guided the development of a conceptual framework for the preparation of an air quality action plan that incorporates such principles in local authorities affected by industrial sources. An action plan can be deemed as sustainable, proportionate and cost-effective if local authorities demonstrate a balance between the scientific assessment of air quality and the social, economic, and political factors in determining and prioritising the proposed management solutions within the plan.
\end{abstract}

Keywords: industrial emissions, LAQM, framework.

\section{Introduction}

This paper examines the application of three principles i.e. sustainability, proportionality and cost-effectiveness within the development of air quality action plans. It focuses on the issue of finding solutions, by applying such 
principles, to air quality problems in English and Welsh local authorities arising, at least in part, from industrial emissions.

The concept of Local Air Quality Management (LAQM) was introduced in Great Britain by the Environment Act 1995 [1]. One requirement of the Act is for the Secretary of State to prepare and publish a statement containing policies with respect to the assessment and management of air quality. This was duly published in 1997 as the National Air Quality Strategy (NAQS) and revised in 2000. Several key principles underpin the NAQS and of these, arguably, the most important are that air quality policy must contribute to sustainable development, and that actions undertaken to secure Air Quality Objectives (AQOs) are proportionate and cost-effective. Table 1 lists definitions of these three principles as suggested by the UK Government $[2,3]$.

Table 1: Definitions of the principles of sustainability, proportionality and cost-effectiveness as set out by the UK government [2, 3].

\begin{tabular}{|c|c|}
\hline Sustainability & $\begin{array}{l}\text { This principle lies behind the drive for technologies, } \\
\text { behaviour and the use of resources which are sustainable } \\
\text { in the long-term. }\end{array}$ \\
\hline Proportionality & $\begin{array}{l}\text { Where the case for action is adequately made, the } \\
\text { measures concerned should be proportionate to their } \\
\text { objectives, in the light of an assessment of the costs and } \\
\text { benefits involved. Measures should provide for flexibility } \\
\text { in implementing and enforcing international obligations. }\end{array}$ \\
\hline Cost-effectiveness & $\begin{array}{l}\text { Decisions must take account of a wide range of costs and } \\
\text { benefits, including those which cannot easily be valued in } \\
\text { money terms. When we cannot put a monetary value on } \\
\text { pursuing any single objective, we should not impose } \\
\text { disproportionate costs elsewhere. We should take into } \\
\text { account public values, the timing of costs, benefits, risks } \\
\text { and uncertainties. }\end{array}$ \\
\hline
\end{tabular}

General advice on the preparation of an air quality action plan is provided by the Government in a Policy Guidance document [4] and the National Society for Clean Air and Environmental Protection (NSCA) with the publications of two guidance documents on action planning [5,6]. These documents do not, however, specifically focus on the application of the above three principles and do not specifically address the preparation of action plans if problems arise from industrial emissions. Figure 1 illustrates the process for developing air quality action plans as suggested by the NSCA guidance documents.

To fulfil the requirement of the 1995 Act (section 82), local authorities in the UK have been conducting a review of air quality within their areas since 1998 and are responsible for conducting an assessment in order to decide whether AQOs are being achieved by specified dates as prescribed in the air quality regulations. If the statutory objectives are not being met authorities have to designate an Air Quality Management Area (AQMA). Within one year of the 
designation, and in parallel with 'Further Assessment' work, the authorities should develop an air quality action plan setting out how they intend to achieve the Objectives. In carrying out their reviews and assessments, and preparing the action plan, local authorities undertake consultation with statutory consultees such as the Environment Agency. Local authorities are now entering the third round of review and assessment (the first round ended in 2003 whilst the second round finished in 2005).

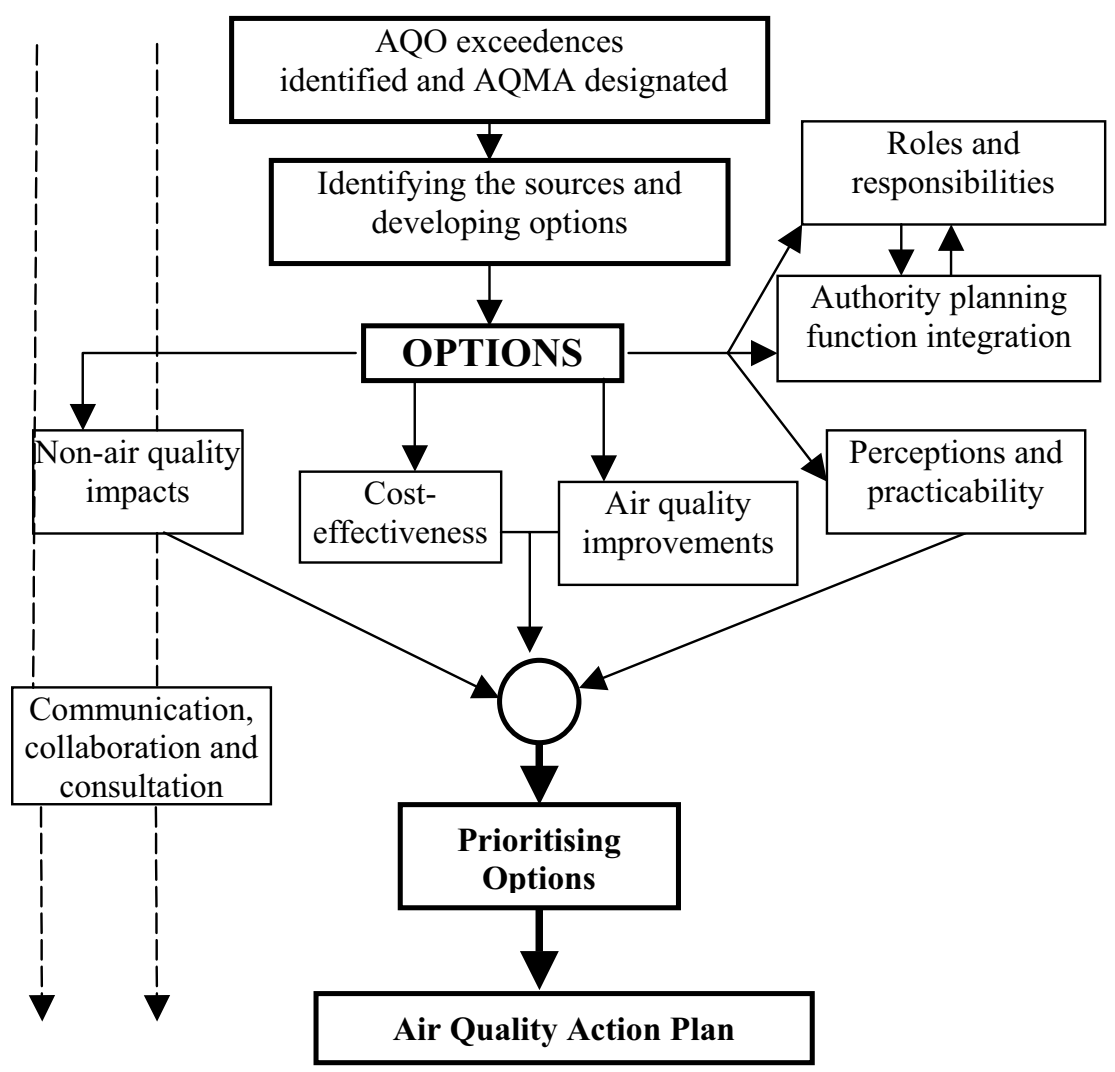

Figure 1: The process for developing air quality action plans $[5,6]$. Note: $\mathrm{AQO}=$ Air Quality Objective; AQMA = Air Quality Management Area.

Responsibilities for controlling industrial installations are shared between the Environment Agency (the Scottish Environment Protection Agency in Scotland) and local authorities. The European Council Directive 96/61/EEC on Integrated Pollution Prevention and Control [7] is currently being implemented in the UK by the Pollution Prevention and Control (PPC) Act 1999 and associated regulations [8]. An industrial installation requires site specific permits which 
consider the characteristics of each industrial plant, location and state of the local environment. To obtain a permit, the installation must ensure that pollution from industry is minimised through the use of Best Available Technique (BAT) (defined as 'the most effective and advanced stage in the development of activities and their methods of operation which indicates the practical suitability of particular techniques for providing in principle the basis for emission limit values designed to prevent and, where that is not practicable, generally to reduce emissions and the impact on the environment as a while' (Regulation 3(1) of the PPC Regulations)) subject to an assessment of costs and benefits. When the Environment Agency determines the authorisation limits for an installation, they must take into account the AQOs. It is essential that the local authorities in their review and assessment work and the regulator of an industrial installation evaluate the extent of any contribution the installation might make to the pollution burden in an AQMA in order to determine the most appropriate measures to include in an air quality action plan.

\section{Methodology}

The data presented here are drawn from questionnaire survey and case study research. Questionnaires were sent by mail to 105 local authority officers, responsible for implementing the LAQM regime in areas considered affected by industrial sources, and Environment Agency officers (Process Industries Regulation Inspectors) where such authorities were located. Five local authorities were selected for case studies. The selection was based on responses given to the questionnaire survey where local authorities were asked about the relative impacts of different air pollution sources to local authority. Case study authorities reported major or minor impacts from industrial installations which then contribute to air pollution problems.

The questionnaire survey provided a broad picture of LAQM practice in local authority areas affected by industrial sources whilst case studies covered a more limited number of authorities but in more depth, in order to understand the application of the principles of sustainability, proportionality and costeffectiveness to the LAQM process. The type of case study used in this research is known as embedded case studies [9], where the case was the process of LAQM in local authorities where air pollution problems arise, at least in part, from industrial sources and particular attention was given to the five selected local authorities. The main source of data collection was semi-structured interview complemented by the government archive on air quality, local authority reports and other documentation related to air quality work in their locality, and questionnaire replies.

\section{Results and discussion}

The survey was used to identify how local authorities worked on air quality action plans. Survey participants were asked to state the measures they intended to take in order to achieve the AQOs (in relation to industrial emissions sources), 
and the stakeholders (within the authorities and outside bodies) who would be their partners during the preparation and implementation of the action plan. This allowed for the identification of any further partnership with the Environment Agency, industry or other departments within the authority.

Table 2 shows the options that local authorities intended to incorporate into their management plans. The most chosen measures to improve local air quality were to seek tighter emission controls and to fit cleaner technology.

Table 2: $\quad$ Action plan options in relation to industrial sources ${ }^{(\mathrm{n}=65)}$.

\begin{tabular}{|l|c|}
\hline Action plan options & Percentage \\
\hline Tighter emission controls & 23 \\
\hline Reduce fuel sulphur content & 9 \\
\hline Cleaner technology & 15 \\
\hline Process relocation & 5 \\
\hline Improve energy efficiency & 14 \\
\hline $\begin{array}{l}\text { Promote the use of Environmental Management } \\
\text { System to Small/Medium Enterprises }\end{array}$ & 12 \\
\hline
\end{tabular}

Table 3 presents the partners with whom local authorities intended to work in developing and/or implementing the air quality action plan.

Table 3: Intended partners in the development of action plans or air quality strategies ${ }^{(\mathrm{n}=65)}$.

\begin{tabular}{|c|c|c|c|c|}
\hline \multirow{2}{*}{ Partner } & \multicolumn{4}{|c|}{ Partnership during (percentages) } \\
\hline & Preparation & Implementation & Both & Total \\
\hline Neighbouring authorities & 31 & 3 & 42 & 76 \\
\hline Environment Agency & 31 & 5 & 22 & 58 \\
\hline $\begin{array}{l}\text { Economic Development } \\
\text { Officers }\end{array}$ & 19 & 5 & 28 & 52 \\
\hline Agenda 21 Officers & 25 & 2 & 37 & 64 \\
\hline Health Authority & 31 & 2 & 22 & 55 \\
\hline Community Group & 32 & 2 & 28 & 62 \\
\hline Industry & 20 & 2 & 31 & 53 \\
\hline
\end{tabular}

Due to the transboundary nature of air pollutants, a local authority may need to work with adjacent authorities or at a more regional level. Around three quarters of the surveyed authorities intended to work in partnership with neighbouring authorities. For a management plan to succeed and achieve its target, a collaborative approach between the main actor and other stakeholders is necessary. More than half of participants stated that they planned to work with the Environment Agency and other internal departments such as Economic Development.

Case studies demonstrated that local authorities have different levels of capability to manage their local air quality. The provision of guidance documents 
and other mean of support from the UK Government does not guarantee a uniform approach to carrying out aspects of LAQM such as AQMA declarations and choosing measures for action plans as these are not exact sciences. Similar sources of industrial emissions, for example a waste management facility, were being dealt with in different ways in terms of technical capabilities and management aspects, including the collaboration with stakeholders.

With regards to the principles of sustainability, proportionality and costeffectiveness, the five case study local authorities applied and interpreted these terms according to their specific situations encountered during the preparation of air quality action plans. The authorities took into account other factors, most importantly socio-economic considerations and political/public support for the proposed management solutions. Case studies also highlighted relatively good collaboration between local authorities and the Environment Agency. In a number of cases, collaboration was not established at the beginning of the LAQM process, but regular communication and co-operation resulted in an improved working relationship and agreements to revise licensing conditions of the industrial sources.

Figure 2 presents a new conceptual model for the preparation of a sustainable, proportionate and cost-effective action plan in local authorities affected by industrial sources, taking into account the framework suggested by NSCA (Figure 1).

This proposed framework is designed to illustrate the necessary preconditions judged to be important for local authorities having air pollution problems arising from industrial emissions to consider in developing their action plans [10]. Sustainability entails integration of economic, social, political elements, and the achievement of AQOs, and a compromise where integration is not possible. The level of compromise is open for debate and discussion. It cannot be generalised but depends on the importance of each element at the right spatial scale.

The conceptual model suggests a better integration between the LAQM and IPPC regimes. Although they are two different regimes, they are closely linked particularly for local authorities with AQMAs due to industrial pollution sources. Linking the two together is considered to be important and clearly there is a need to streamline the processes in LAQM and IPPC.

The framework starts with a predicted AQO exceedence due to industrial emissions. It is important for a local authority to identify relevant stakeholders at a very early stage of the process. As the exceedence is identified, the IPPC regime should acknowledge that an industrial source may be contributing to this exceedence. Acceptance of the problem opens the door of communication between local authorities, the Environment Agency and the industrial operator. The regulator (local authorities or the Environment Agency) needs to assess the contribution from the industrial process and this can be done in conjunction with Further Assessment work. Depending on the extent of the contribution identified, the regulator should review the authorisation conditions. At this stage, it is useful to re-identify stakeholders. Throughout the whole process, appropriate consultation with relevant departments within the authorities, politicians and the 
public is necessary, as is regular communication between local authorities, the Environment Agency and the industrial operators to ensure a high level of collaboration. All stakeholders should be involved when choosing and prioritising options for the action plan. The Government advise local authorities to demonstrate that the proposed options will bring sufficient air quality improvement to deliver AQOs [4]. However, case studies revealed that decision making needs to reflect a wider consideration of socio-economic and political factors, rather than dealing exclusively with the scientific review and assessment of air quality.

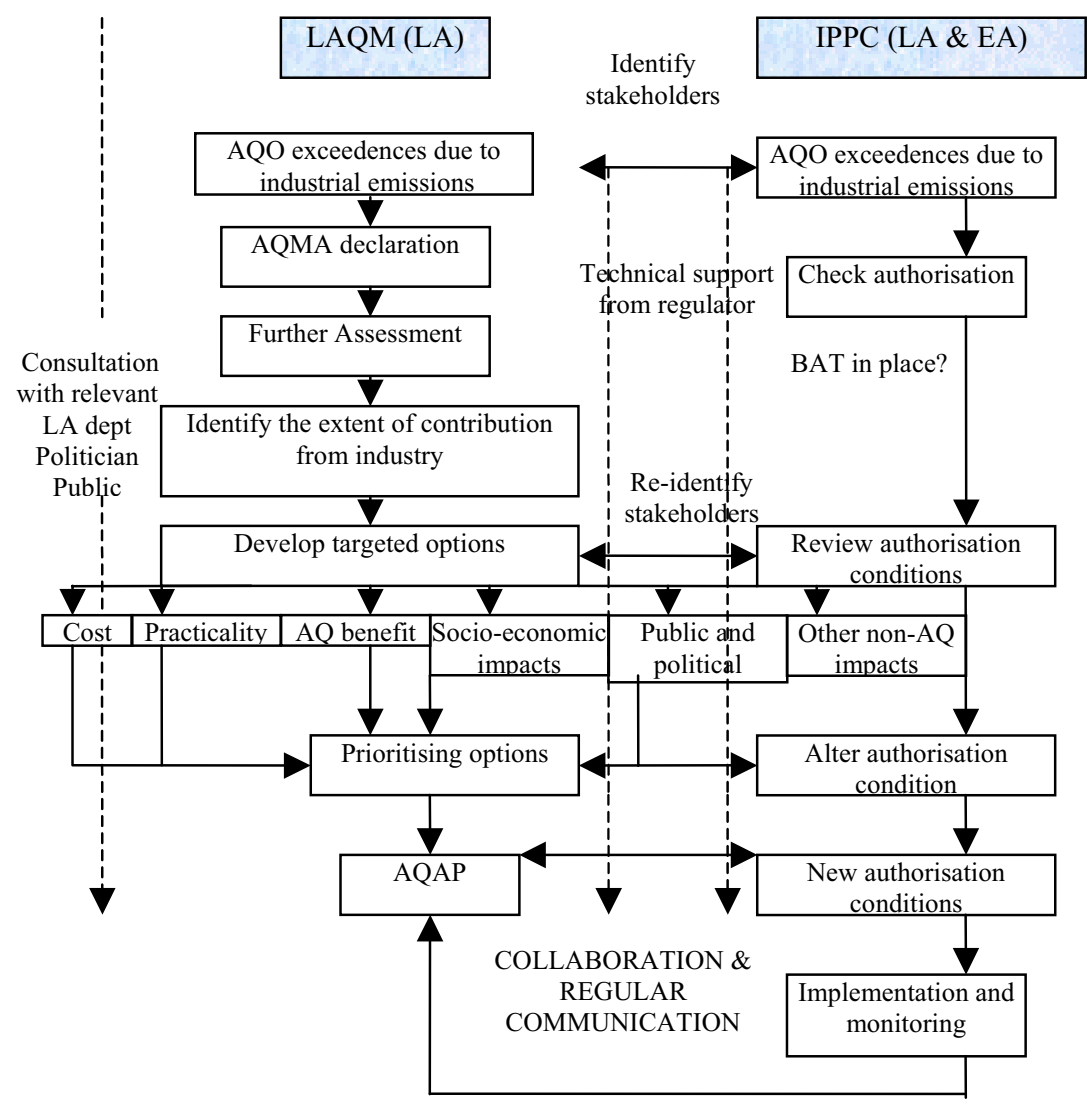

Figure 2: A conceptual framework for the preparation of a sustainable, proportionate and cost-effective action plan in local authorities affected by industrial sources [10]. Note: LA = local authorities; $\mathrm{EA}=$ Environment Agency; AQO = Air Quality Objective; BAT = Best Available Technology; AQ = Air Quality; AQAP = Air Quality Action Plan. 
Elements considered in this model include air quality benefits, cost, practicality, socio-economic impacts, political/public support, and other non-air quality factors. These factors were identified to be important in the local authority decision-making processes. From the IPPC point of view, the outcomes are new conditions to the authorisation which represent the local authority's air quality action plan.

\section{Conclusions}

Evidence from the questionnaire survey and case studies were presented to examine the LAQM process in local authorities experiencing air pollution problems arising from industrial sources. Within the development of air quality action plans a conceptual framework has been proposed to enable such authorities deal with air pollution problems. The framework proposes better integration between the two air pollution control regimes: LAQM and IPPC. Local authorities applied and interpreted the principles of sustainability, proportionality and cost-effectiveness according to their own local situation experienced during the preparation of action plans. It is difficult to define such terms in an operational sense but this paper argues that an action plan can be deemed as sustainable, proportionate and cost-effective if local authorities demonstrate a balance between the scientific assessment of air quality and the social, economic, and political factors in determining and prioritising the proposed management solutions within the plan.

\section{References}

[1] HM Government (1995) Environment Act 1995. Chapter 25, The Stationery Office Ltd, London.

[2] DETR (1997) The United Kingdom National Air Quality Strategy, The Stationary Office Ltd, London.

[3] DETR, Scottish Executive, National Assembly for Wales, and Department of the Environment for Northern Ireland (2000) The Air Quality Strategy for England, Scotland, Wales and Northern Ireland - Working Together for Clean Air. CM 4548, The Stationary Office Ltd, London.

[4] Defra and National Assembly for Wales (2003) Part IV of the Environment Act 1995 Local Air Quality Management. Policy Guidance LAQM. PG(03), Defra, London.

[5] NSCA (2000) Interim Guidance on Air Quality Action Plans, NSCA, Brighton.

[6] NSCA (2001) Air Quality: Planning for Action. Part 2 of the NSCA's Guidance on the Development of Air Quality Action Plans and Local Air Quality Strategies, NSCA, Brighton.

[7] Council of the European Union (1996) Council Directive 1996/61/EC of 24 September 1996 on integrated pollution prevention and control. Official Journal of the European Communities, L 257, pp. 26-40. 
[8] HM Government (1999) Pollution Prevention and Control Act 1999. Chapter 24, The Stationery Office Ltd, London.

[9] Yin, R.K. (1994) Case Study Research. Design and Methods, $2^{\text {nd }}$ Ed, Sage, London.

[10] Leksmono, N. (2005) Sustainable, Proportionate and Cost-effective Action Plans to Deliver Air Quality Objectives within Air Quality Management Areas, PhD Thesis, University of the West of England, Bristol. 